\title{
Effect of Erosion on Agricultural Land in Agyana Community in Abaji, Abuja
}

\author{
Jibrin Ahmadu, Daniel Habila Galadima, Nkechi Blessing Chinedu, Ogechukwu Franca Eze
}

Department of Pollution Control and Environmental Health, Federal Ministry of Environment, Abuja, Nigeria

\section{Email address:}

Jigbane2@gmail.com (J. Ahmadu), dhgaladima3362@gmail.com (D. H. Galadima), kechisclouds20@yahoo.co.uk (N. B. Chinedu), francaking.o@gmail.com (O.F. Eze)

\section{To cite this article:}

Jibrin Ahmadu, Daniel Habila Galadima, Nkechi Blessing Chinedu, Ogechukwu Franca Eze. Effect of Erosion on Agricultural Land in Agyana Community in Abaji, Abuja. International Journal of Applied Agricultural Sciences. Vol. 5, No. 5, 2019, pp. $120-128$.

doi: 10.11648/j.ijaas.20190505.14

Received: August 13, 2019; Accepted: September 24, 2019; Published: October 16, 2019

\begin{abstract}
This study has investigated the effect of erosion on agricultural land in Agyana community of Abaji Area Council in Abuja, Nigeria. In this task, the study was able to operationalize the independent and dependent variables and do a structured observation and perform reliability checks on the accuracy of the observations made. In determining the area of land affected by erosion in the study area, proper measurement of land affected was done with the use of measuring tape. The measuring tape that was used was calibrated in meters and in feet. In the course of this study, the measurement carried out was done in meters. The findings are clear manifestation that the objectives set and the relationship between soil erosion and human activities have held true. That erosion has significant relationship on human activities: This is because there is loss of soil more rapidly than it is formed through natural processes. This result in losses of soil organic matter, fertility and water holding capacity. The effect of soil erosion is on the increase despite remedial measures taken by farmers to control it. locally, problems associated with the persistent erosion in the affected areas result in declining standard of living as there is low yield per hectare.
\end{abstract}

Keywords: Effect, Erosion, Agricultural, Land and Agyana Community

\section{Introduction}

\subsection{Background of the Study}

Recent happenings in the world have shown that soil erosion is ravaging every part of the world. Soil erosion is by far one of the most identifiable problems of the world, high intensity rainfall or strong winds may trigger off soil erosion resulting in soil improvement.

The first known occurrence of the term 'Erosion' was in 1541 translated by Robert Copland of Guy de Chaulic's Medical Text "The Questynonary of Cyruryens. Copland used erosion to describe how 'Ulcer's developed in the month. Then by 1774 , erosion was used outside medical subjects, then Oliver Goldsmith employed the term in more contemporary geological context, in his book; Natural History' with the quote "Bounds are thus put to the earth by water".

Soil erosion is common in most parts of Nigeria and the world as a whole, rainfall though short-lived may be heavy enough to create irretrievable changes in the landscape. However, the role of rainfall as an agent of erosion depends on human impacts on the environment. Many forms of land use are known to result in degrading trend changes especially in areas where slopes are steep, soil are shallow and rainfalls are heavy and concentrated in short periods.

Research has shown that the Eastern and Western parts of Nigeria are mostly hit by this menace. This has for long been in the work of Ofomata [1] who took Enugu as a case study. But this is not to say that other parts of the country are not affected, no part of Nigeria is left out of the problems. This is the reason why this study is designed to examine the impact of Erosion on land.

Adediji [2] describes soil erosion as a process of detachment of soil material as well as its transportation by water, wind and ice. He went further to explain that soil erosion is a natural process which always assumes the form of sheet, rill or gully. It is basically classified into two major 
types which include normal geological erosion and accelerated soil erosion. However, a distinction is usually made between the two; while the latter results largely from human influences and is faster in occurrence, the former on the other hand is slow and involves denudation agents such as running water, wind, ice. Even though occurrence of soil erosion is due either to natural or human factors, more frequently it occurs as a result of the intimate mixture of the two factors.

FAO [3] identified six major causes of soil erosion. These causes include; deforestation, shortage of land due to increase population, poor land use management, insecure land use tenure, inappropriate land management and poverty.

Gruver [4] believed that excessive use of land for cultivation has accelerated the loss of organic matter which made the soil susceptible to wind and water erosion and they also further explained that this accelerated erosion results in loss of soil fertility. However, according to Kumar and Pani [5], the balance between soil-forming and depleting processes is of utmost importance for attaining long-term sustainability in any production system. Land degradation in the form of soil erosion has been reported as a major problem in the semi-arid region of Lower Chambal Valley [5].

FAO [6] unveils three primary effects of erosion on crop growth and yield to include: removal of the fertile surface soil horizon, incorporation of denser subsoil into the surface layer, and a possible decrease in the rooting zone of the soil. The submission by FAO [6] concurs with prior assessment by Panagos et al [7] which highlights specifically that soil erosion changes the physical, chemical, and biological characteristics of soil, leading to a drop in potential agricultural productivity and gives rise to concerns about food security, especially in the context of a growing world population.

\subsection{Statement of the Research Problem}

Land degradation is the decline in the rate at which land yields products to local livelihood is been affected [8]. In low-input agricultural systems the most important forms of land degradation are soil and vegetation degradation [9]. Soil degradation, that is, the loss of soil productivity, often occurs due to land-use changes. Where cropland replaces natural vegetation and land management is inappropriate, this leads to reduced infiltration rates, higher runoff and erosion and thus continued land degradation. In uncultivated areas vegetation degradation, i.e. the decrease or removal of vegetation cover often precedes soil erosion.

In Agyana community of Abaji Area Council, FCT, soil erosion has occurred over the generations and the situation has been aggravated as a result of the substantial increase in human population in the area following the creation of Abuja Federal Capital Territory. During the 1980s and 1990s there were alarming reports about extreme soil erosion occurring across the Abuja region where Agyana is located.

Hence, soil erosion seems to be grave problem and would expect a lot of action to tackle it. However, the reality is different. Projects activities and budgets-rather than being spent on countering soil erosion are mainly focused on the construction of schools, roads, playgrounds and market. Long-term impact reduction activities like those related, to soil and water conservation (SWC) is seldom mentioned.

Although, erosion studies report severe erosion rates apparently endangers the future sustainability of local livelihoods and institution, the people act indifferently. Considering this general passivity, the question arises; is soil erosion really a serious problem in Agyana community? Even more important, we must know how the residents of the community perceive soil erosion and its effects. It has variously been observed that if evidence for soil erosion is not being as widespread as it was presumed to be, it is possible for the people to hesitate in adopting SWC practices [10].

For the correct assessment of soil erosion in Agyana, more level assessment needs to be made involving in particular assessment of the views of the area residents. Moreover, local people's knowledge has proved to be very useful in land degradation assessment [11]. This study thus makes a step towards filling this gap.

Therefore, with the objective of exploring the seriousness of soil erosion in Agyana community, this study explores the feasibility of using a methodology in which the local people were directly involved in assessing soil erosion causes, effects and management.

\subsection{Aim and Objectives of the Study}

The aim of this study is to assess the effect of soil erosion in Agyana community of Abaji Area Council, FCT. In specific terms, the objectives of the study are:

To estimate the size of the land affected.

To identify land uses affected.

To identify and examine the control measures in checking soil erosion.

\subsection{Geographical Charateristics of the Study Area}

\subsubsection{Location}

This study covers Agyana community in Abaji Area Council, in the Federal Capital Territory FCT, Abuja and shares boundary with Kuje to the West and South West, Gwagwalada to the North, Kwali to the East and South East and is located within latitude $8^{0} 25^{1}$ and longitude $6^{0} 45^{1}$ and $7^{0} 39 \mathrm{E}$.

\subsubsection{History and Ethnic Characteristics}

The major ethnic group is Gbagyi, there are two main types of Gbagyi, namely,

i. The Yanma (The Southerners)

ii. The Genge (The Northerners)

To quote from a report on Pagan Customs, Administration and Judiciary of the Gbagyi tribe in Abuja, (30 ${ }^{\text {th }}$ March 1939) the southern boundary of the Gwari-Yanma could be demarcated by a line drawn south from Paiko to Lapai, east to the River Gurara and then south down the river itself. Along the south-western and southern borders of Abuja Emirate, they share the country with the Bassa and Gads 
respectively.

Gbagyi Yanma had come to Abuja from Paiko and then Gawu and Izom, the Gbagyi Genge had gone there from the North-East via Borno, Plateau and Zaria, but both met the Koro in Abuja.

The Gbagyi of the Abuja province indeed founded or settled in a number of communities which grew in size and importance with time. Most of these communities had been originally shifted from their very locations to new areas especially on the note of the establishment of the FCT some of the communities include Ija, Bwari, Ushafa, Garki, Diko and Gwako.

The Gbagyi inhabit the central part of Nigeria, in today's political arrangement, they are found in Kaduna, Niger, Plateau and Kwara State. In Kaduna, they are found in (Birnin Gwari, Chuku, Kaduna, Kakarku, and Sarkin Pawa). In Niger (Galadima Kogo, Minna, Paiko). In FCT (Kwali, Abaji, Bwari, Kuje, Gwagwalada, Karshi)

The Gbagyi's are related to their neighbours on areas of:

i. Common Origin

ii. Religious Similarities

iii. Trade Association

iv. Similar Language

v. Inter-marriage

vi. Similar political culture

vii.Facial marks

The Gbagyis were able to maintain groups because of their acknowledge virtues.

i. Accommodation

ii. High flare for mobility

iii. Peacefulness and non-violence

iv. Respect for occupation

v. Respect for culture

The virtues are still noticeable among the Gbagyis and the mutual relations between them and their neighbours have not dwindled. Indeed, it has only grown from strength to strength.

\subsubsection{Economy}

The economy of the local government area like that of most local government in the state is agrarian based, most crops produced in most agrarian society is for subsistence and only the excess get into the market to meet the needs of others. Crops produce include yams, maize, millet, guinea corn, beans, melon, groundnut, in addition to fruits like citrus, mangoes, guava which are grown in commercial quantities.

\subsubsection{Climate}

The area experiences the humid climate type which is characterised by seasonality in rainfall and temperature distribution. Daily average temperature is $37^{\circ} \mathrm{C}$ characterised by two seasons, the wet and dry season. The wet season (rainy seasons) last 8-months starting from April to MidOctober and 4 months of dry season starting from October ending late March. The area also experiences from November to February the North East Trade Wind which ushers in the harmattan season.

\subsubsection{Human Activities}

The land is used for agriculture which is practiced by crude method involving the use of hand tools or implements such as hoes (Zukwo in Gbagyi) cutlass (apiya), cutlasses, shovels and diggers. A variety of crops grown such as yam, maize, guinea corn etc. are grown and other different kinds of vegetables such as green leaves spinach and okro.

The inhabitants of Agyana community are also involved in the use of fire wood as a source of energy for domestic cooking. The use of fire wood in the community has greatly affected the growth of trees in the community. The local women, have also resulted in selling fire woods from the trees they fell in other to meet their financial need to support the family. Forest conservation practices are not embraced by the community because of their practices.

\subsubsection{Soil}

The soil is predominantly laterite in nature which is underlined by mottle concertino in the lower profile, the soil of the study area consists of humus soil which is good for vegetation. Because of over use and deforestation most soil is deficient in humus on the surface horizon. This makes the soil to become compact and thus drainage is impeded, heavy to cultivate and low agricultural productivity and as such requires application of additives to improve its agricultural potential, under such soil run off and erosion is a common phenomenon. In other areas of the community, sandy loamy soil is seen. In these areas, the impact of erosion is not felt much because the land is put into the cultivation of cover crops like groundnuts and beans.

\section{Literature Review}

\subsection{Soil Erosion}

Erode means eat away, wear out or to destroy the surface. Erosion is the product of erode. Land degradation is any variation to the original land that diminishes the land value and productivity. There are many types of land degradation such as wind, water, overgrazing, dry land, salinity, soil acidification, irrigation and water logging, the replacement of natural vegetation with pasture, soil structure decline and clearing of natural vegetation.

When all vegetation has been removed from the soil, the soil is left exposed to the element leaving it bare and loosening the soil particles. The soil is then easily blown away; leaving poorer quality sub-soil to remain this is a serve problem in the nation as a whole.

Adedeji [2] defines erosion as a process of the detachment of soil materials as well as its transportation by water, wind or ice. He further explained that erosion is in different forms which include splash, sheet, rill and gully.

Strahler [12] observed that soil erosion is a natural phenomenon which varies from one area to another. He identified two forms of soil erosion namely normal geologic and accelerated types. Normal geologic erosion involves the slow removal of soil by various denudational conditions. Accelerated soil erosion occurs where man has tempered 
with the environment especially through the removal of vegetation cover.

To White [13], soil means the removal and transportation of soil constituents by natural forces, primarily water and wind.

Ofomata [1] sees soil erosion as a geo-morphological process whereby the surface layer weathered and weathering rock is loosed, carried away by wind and running water and a lower horizon in the soil is exposed under natural conditions.

\subsection{Erosional Process}

Erosion is the displacement of solids (soils, mud, rock and particles), usually by the agents of currents such as wind, water or ice by downward or down slope movement in response to gravity or by living organisms (in the case of bioerosion) [14].

Erosion is distinguished from weathering which is "the breaking down of rock and particles through processes where no movement is involved, although the two processes may be concurrent.

\subsubsection{Erosion Process by Running Water}

Water erosion is due to the force of running water, heavy rainfall and such events include flash flooding where sudden rainfall can occur several kilometres away, the water sweeps down, taking with it everything in its path. They uproot trees, move boulders and demolish bridges and building along with the precious topsoil which is very dangerous.

\subsubsection{Sheet Wash or Surface Wash}

Akanro [15] looked at sheet erosion as a dynamic phenomenon, resulting from detachment of soil from the earth's surface by rainfall and the subsequent transportation by overland flow.

Faniran and Areola [16] viewed erosion as the thin layers or sheets of soil from a sloping land, he said it is a rather inconspicuous type of erosion because the total amount removed in any storm is usually small; however, the cumulative effect can be very disastrous if not checked.

\subsubsection{Inter Rills and Channel Flow}

Rill erosion as the removal of soil by water from small but well-defined channels or streamlet when there is a concentration of overland flow. Rill erosion is small enough to be easily removed by normal tillage operations. They share the same view that slope also accelerates runoff velocity among other factors like intensity and duration of rainfall, texture to mention but a few, these effects combines to form inter-rill.

\subsubsection{Gully or Ravine Erosion}

If the volume of water in the rills enlarges, relatively large gullies develop. Gully erosion occurs if considerable water flow is accompanied by some cutting and abrasion [13]. Then further down at the slope at favourable locations rills or micro-channels join to make larger channels with greater discharge and greater erosion powers, at this stage, rill erosion changes into gully erosion.
The soil mantle is eroded by gully action through the deepening head ward recession and widening of the gully. Thus, the eroded area becomes progressively deeper and wider. At advantage stage small gullies develop into larger ravines which may be 50 to $100 \mathrm{ft}$ deep and with steep almost vertical sides.

\subsubsection{Interflow}

This is a subsurface flow; it is erosion by gravitational water after heavy down pours. This type of erosion is predominantly in area where flow is concentrated into underground drainage channels called percolines. This type of process of water erosion is associated with savannah soil with duplex profile forms of sand over clay.

\subsubsection{Erosion Processes by Moving Wind}

When soil particles are picked up and carried down and deposited when the winds clam down are known as wind erosion/deposition. The Aeolian particles deposited by winds are capable of forming a deep soil parent material called loses, the silt and clay particles that go less may come from distant lands.

Strong wind usually eroded soil through deflation and the process is important in removing fine materials leaving a coarse lag deposit. The result of materials moved by the wind is of two main effects.

i. Wind causes small particles to be lifted and therefore moved to other region which is called deflation.

ii. These suspended particles may impact on solid objects causing erosion by abrasion, wind erosion generally occurs in areas with little or no vegetation, often areas where there is insufficient rainfall to support vegetation. An example is the formation of sand dunes on a beach or in the desert; windbreak is often planted by farmers to reduce wind erosion.

\subsubsection{Siltation}

This involves mainly medium to fine sand and coarse silt, here the particles are transported near ground level by series of hops and bounces. Particles remain in the air for one or two seconds after which they fall back to the ground only to be lifted again.

\subsubsection{Traction}

This is known as surface drag; it involves mainly coarse sand particles which are too heavy to be transported. Wind force is only able to roll these particles along the ground without actually lifting them.

\subsubsection{Causes of Soil Erosion}

Soil erosion is either due to natural or human factors but more frequently as a result of the intimate mixture of the two factors. Excessive use of land for cultivation has accelerated the loss of organic matter made the soil susceptible to wind and water erosion, which accelerated erosion result in loss of soil fertility.

The rate erosion depends on many factors, including

i. The amount and intensity of precipitation

ii. Texture of the soil 
iii. The gradient of the slope

iv. Ground cover from vegetation

v. Rocks

vi. Land use

vii.Possibility of erosion from speed of a stream

Soil erosion is caused by many factors: the main elements of climate which affects the rate of erosion are rainfall and wind temperature. The most prominent among the causes of erosion is the destruction of vegetation.

Study of soil erosion in the Eastern part of Nigeria also attributed the causes to activities of man on the earth surface these activities include road construction, mining, overgrazing and others. The natural factors responsible for soil erosion are the steep slope and soil erosion is that it facilitates the fast movement of surface runoff. Areas with steep slope like plateau experiences severe gully erosion particularly where the surface cover is bare cleared of vegetation, bush fires and overgrazing.

Similarly, in the view, both steepness and length of the slope erodibility. Because of the greater potential energy of soil and water high on the slope which can be converted to kinetic energy. The larger or longer the slope, the greater the surface runoff and its downhill velocity. Soil erosion depends on the force with which the water acts upon the soil (erosivity) and the degree to which the soil can resist the force (erodibility).

Other physical factors include;

i. Heavy rainfall

ii. Strong winds

iii. Soil susceptibility

iv. Flood

v. Water repellent soils

vi. Prolong drought

vii. Stream rejuvenation

Human factors include;

i. Deforestation

ii. Bush burning

iii. Soil tillage

iv. Overgrazing

v. Open cast mining

The causes of soil erosion in Nigeria has been attributed to the increase in population and that as the pressure on land increases due to rise in population, the problem of soil erosion becomes eminent. The cause also arises from torrential rains characteristics of many parts of Nigeria, no doubt this contributed to the incidence of soil erosion.

In many erosion prone areas of southern Nigeria, the average rainfall is about $200 \mathrm{~mm}$ a year with raining season of about eight months. It was noted that regular and often intense storms falling on exposed soil surface have added their destructive force to those of other climatic elements, this leads to excessive leaching of the soil horizon which is followed by wholesale removal of topsoil through sheet and gully erosion.

Soil erosion is caused by removal of vegetation cover for road construction, thereby exposing the bare surface to denudational agents such as rainfall. And that both length and degree of slope are also responsible for soil erosion as such is more prominent on steeps slopes leading excessive loss of productive soil materials.

\subsection{Consequences of Soil Erosion}

Soil erosion has profound effects on the physical processes of infiltration surface runoff and water holding capacity of soils. It also affects farming and farming practices, e.g. spray irrigation, drainage, fertilizers and feed. Studies conducted on soil erosion have shown that it is accompanied by serious environmental consequences.

It was observed that all forms of land degradation by soil erosion leading to food shortages which may have adverse effects on the populace. It was argued that to a considerable extent, the loss of soil from cultivated land as a result of soil erosion contributed to the decline in agricultural production in Nigeria.

Soil erosion result not only in the physical removal of surface soil, but also in losses of organic matter and nitrogen components. In addition to nutrients losses, the moisture retention characteristics, infiltration rate are significantly affected.

Soil erosion has become a serious danger to both life and property and has led to loss of several homes and household properties as well as cultivated crops.

Igbozurike [17] stated that the declining stage of forest wealth and heritage in Nigeria constitute a threat to soil fertility, agricultural productivity and quality of life in general. He added that soil erosion has led to the progressive deterioration of productive farmland, resulting in declining farm incomes according to him, the problem has caused discouragement, farm abandonment, debt and bankruptcies in some of the severely affected countries.

Erosion is soil's worst enemy for many reasons such as:

i. It strips the soil of the nutrients rich in topsoil

ii. It removes vegetation from places where it's already established

iii. It clogs surface water strangling aquatic habitat

iv. It can leave mud on the road

v. It also displaces sediment to unwanted areas.

\subsection{Control Measures of Soil Erosion}

The key to stopping erosion is to anchor moving across it. The best way to hold soil in place is to plant vegetation in the soil, establishing a ground cover which has many benefits besides controlling erosion grass shrubs and trees are all effective ground covers.

Reliable and proven soil conservation technique include ridge planting, inter-cropping, cover crops residues and mulching, wind breaks, rain harvesting, strip cropping, terracing and contour farming. These can be grouped as vegetative, agronomic and mechanical measures.

a. Ridge Planting: Reduces the need for frequent tillage and also leaves vegetative cover on the soil surface year-round [18].

b. Inter-Cropping: Different types of crops with different 
maturing time sometimes planted together to avoid the exposure of much bare ground. For example, in Northern Nigeria, groundnut or beans are sometimes planted between rows of millet, maize or guinea corn, this is so because beans will help revive soil fertility and structure [20].

c. Cover Crops: As recommended by Constantinesco [18], the best way to control erosion is to keep the land covered; the main advantage of this method is that it protects the soil from erosion by both rainfall and wind. It decreases the volume of soil particles dislodged due to rain and other natural forces, it slows the flow of water across the soil, it slows scouring effect movement soil has across the soil the yard and it provides buffer that acts as a filter, decreases the movement of sediment and other materials like pesticides and fertilizers. It has the benefit of addition of organic matter, aesthetic valve and wildlife benefit.

d. Crop Residues and Mulching: Cover the soil with the crop residues such as straw and stubble of grain crops and grasses or banana leaves residue soil losses very considerably. Residues hold considerable amount of water at the soil surface and tend to retard flow which allows more time for water to infiltrate into the soil.

e. Wind Breaks: In areas liable to wind erosion trees are planted in line along farm boundaries to break the speed of wind thus, reducing its erosive force. Alternatively, farm boundaries can be marked with other forms of vegetative barrier as bushes or hard grass.

f. Rain Harvesting: This is practiced in arid and semi-arid areas, the practice attempts to reduce runoff to almost nil in the following ways paddles, micro-catchments, bounds and furrows are constructed to hold rainwater. This encourages plant growth and reduces deflation by wind.

g. Strip Cropping: Strip cropping is the practice of planting alternate with close growing meadow, row or gain crops following the contour across a slope. The system is used on slopes that are too steep to terrace, like contouring, strip cropping slows down run-off water through the close growing step and so increase the infiltration rate which further rate which reduces the total runoff.

h. Terracing: Terrace agriculture involves building earth embankments or a combined channel and embankment across the slope, usually at fixed intervals. It may also involve creating flat or near flat surface along very steep slope, the latter is called bench terrace and is much more tedious task which undertaken where embankments and channels cannot stop runoff on very steep slopes. Terrace is an effective way to control erosion by reducing slope length as well as slope steepness (bench terrace) and slowing down runoff.

i. Contour Farming: Contour farming is the practice of planting rows or operating farm equipment across the slope. This helps to converse soil and water as the rows of ridges or crops or both acts to check water flow. Based on the principle of sustainability in production and soil conservation.

j. It was observed that good farming practices, rational land use and efficient management of soil, crops and livestock result in sustained high yield. For the soil to maintain high yield, it must be properly conserved by adoption of the conservation practices and techniques.

\section{Research Methodology}

\subsection{Sources of Data}

The two main sources of data used in this research work are;

i. Primary Sources of data

ii. Secondary Sources of data

The choice in the sources of data is necessitated by the nature and the scope of this research.

\subsubsection{Primary Source of Data}

The Primary data are sourced from the field investigation, which involves a primary contact with the elements being investigated. The primary data were obtained through the use of measurements and questionnaire administration

\section{(i). Questionnaire Administration}

Administration of questionnaire is extremely demanding in terms of time and resources. Hence, questionnaire meant for the collection of primary data as in this case was made brief, concise and precise. The longer a question becomes the more likely that the respondent will get bored of answering questions; that the interviewers will get bored and slapdash; that checking, coding and data entry will take too long; and that data analysis will lose direction in an attempt to sift out what is essential.

The questionnaire administered contained variables to be investigated, that includes length and depth of erosion site, farming practices and the types of crops planted.

\section{(ii). Field Observation}

In this exercise, first, an unstructured observation was conducted for 30-60 minutes. In this task, the researcher had to train himself as many concrete behaviours without filtering them through any interpretive process. In the second part, the researcher was able to operationalize the independent and dependent variables and do a structured observation and perform reliability checks on the accuracy of the observations made.

\section{(iii). Measurement}

In determining the area of land affected by erosion in the study area, proper measurement of land affected was done with the use measuring tape. The measuring tape that was used is calibrated in meters and in feet. In the course of this study, the measurement carried out was done in meters. 


\subsubsection{Secondary Data}

Secondary data are data that have been collected other than the ones collected by the researcher. Some time, secondary data may be raw data, collected and stored by an organization in the normal course of their operations such as primary school enrolment by local inspectors of education, population data and medical records among others. It may also be data already processed and released to the public or kept in custody by public or private organisations.

\subsection{Sampling Technique}

For the purposes of selecting samples, the random sampling technique was used to compile the list of all items (units) making up the population. Each unit was assigned an identification number. The identification started from one (1) and continues and the desired number of units for the sample was selected using the following methods;

A table of Random Number was used to select the units: This is achieved by reading off the table of random numbers by given appropriate digits. A simpler way in achieving this is to write the identification number of all units on pieces of paper or put in a hat, basket or box. These pieces of papers are properly shuttled and samples can then be drawn by picking unit identification numbers out of the hats, baskets or box. The units are drawn one at a time until the sample size is completed. The units so selected are the sample for the survey. All of these or only these units are to be interviewed; no unit maybe excluded or substituted for any reason.

The advantage drawn from this technique is the usefulness when population is homogenous, fairly small and sampling frame is complete.

It is less expensive and less time consuming compared with simple random sampling technique and it is easier to use on the field.

The disadvantages of this method are, the method is not purely random because of the pre-selection of the subsequent sample units. It may unintentionally lead to the elimination of certain units. This means that it does not give equal chance of being selected to the units.

\subsection{Method of Data Analysis / Procedures for Processing Collected Data}

Descriptive statistics (such as frequency distribution, and percentages) were used to determine the relationship between the variables. Thus, percentage method of analysis was used to analyze the data. As identified in Chinedu [19], "the percentage method is widely used in managerial and social researches". According to the report, the formula is:

$$
\mathrm{A} \%=\frac{\mathrm{a}}{\mathrm{N}} \times 100
$$

Where:

$\mathrm{A} \%=$ the percentage of responses to one option over the total responses to the item.

$a=$ number of responses to one option of each item of the questionnaire

$\mathrm{N}=$ total number of responses to an item.

For example, assume the total number of responses $(\mathrm{N})$ is 100 and the number of responses to one option (a) is 50 then.

$$
\mathrm{A} \%=\frac{\mathrm{a}}{\mathrm{N}} \times 100=\frac{50}{100} \times 100=50
$$

\section{Results}

This section presents and discusses the results of the survey conducted. The results are summarized in five tables, with Table 1 presenting data on the socio-economic profile of the respondents. Table 2 presents data on the respondents observed rating of changes in Agyana and its environs. Table 3 presents data on respondent rating of the study area in terms of the changes they have been observing in the environment around them. Table 4 presents data on forms of changes found on the landscape while Table 5 presents data on features on which the changes were observed by the respondents.

\subsection{Socio-Economic Profile}

The population of the community are more of younger people and this means that most of them are within the active group, engaged in socio economic activities likely to lead to land erosion in the area. (Table 1)

Table 1. Socio Economic Variables.

\begin{tabular}{lll}
\hline Options & Frequency & Percentage of the total \\
\hline Age & & \\
$15-30$ years & 60 & 40.0 \\
31 - 45 years & 57 & 38.0 \\
Above 45 years & 33 & 22.0 \\
Total & 150 & 100 \\
Occupation & & \\
Farmers & 48 & 32.1 \\
Civil Servants & 44 & 29.3 \\
Businessmen & 32 & 21.3 \\
Students & 26 & 17.3 \\
Total & 150 & 100 \\
Monthly Income & & \\
Below 500 Naira & 20 & 13.3 \\
501 - 1000 Naira & 18 & 12.1 \\
1001 - 5000 Naira & 44 & 29.3 \\
5000 Naira above & 68 & 45.3 \\
Total & 150 & 100 \\
Size of Household & & \\
0 - 3 Children & 33 & 22.1 \\
3 - 6 Children & 37 & 24.6 \\
Above 6 Children & 80 & 53.3 \\
Total & 150 & 100 \\
\hline
\end{tabular}

Source: Field work, 2014

The result of the survey, for example, shows that 40 percent of the people are between ages 15 and 39 years. 


\subsubsection{Age Distribution}

The distribution of age by population as indicated in table 1 shows that $40 \%$ of the population with 60 respondents constitute the majority (within the age of 15 30). This however, shows that people within this group are young in age which can lead to socio - economic growth and stability.

\subsubsection{Occupations}

The distribution of occupation in table 1 indicates that $32 \%$ with 48 respondents who are farmers and engage in agricultural production. $29.3 \%$ with 44 respondents who are civil servants, $21.3 \%$ with 32 respondents being business men, while the least occupation with $17.3 \%$ whose respondents are students. From the above analysis, the percentage of the occupation are predominantly farmers which is likely to lead to erosion.

\subsubsection{Monthly Income}

Table 1 shows the monthly income of respondents. The table indicates that $45.3 \%$ with 26 respondents (fall within 5000 Naira income and above), 29.3\% with 32 respondents (fall within 1001-5000 income) while $13.3 \%$ with 48 respondents (fall below 500 Naira income) and $12.1 \%$ with 44 respondents (fall within 501-1000 Naira income).

This reveals that $45.3 \%$ with 26 respondents earning 5000 Naira and above have a role to play in socio-economic activities as a result of their high income.

\subsection{Environmental Changes}

Environmental changes are changes that are perceived to occur in the area as a result of

\subsubsection{Observed Changes}

Observed changes in the study area are more noticeable in the area of agricultural practices, which accounts for 32.6 percent of the total observed changes.

Table 2. Observed Changes.

\begin{tabular}{lll}
\hline Options & Frequency & Percentage of the Total \\
\hline Agricultural productivity & 49 & 32.6 \\
Building & 45 & 30.0 \\
Roads & 29 & 19.3 \\
All of the above & 27 & 18.1 \\
Total & 150 & 100.00 \\
\hline
\end{tabular}

Source: Field work, 2014

\subsubsection{Rating of the Changes in Terms of Intensity}

Table 3. Rating of the Changes in terms of intensity.

\begin{tabular}{lll}
\hline Options & Frequency & Percentage of the Total \\
\hline Strong & 29 & 19.3 \\
Moderately Strong & 44 & 29.1 \\
Very Strong & 29 & 19.3 \\
Mild & 48 & 32.3 \\
Total & 150 & 100.00 \\
\hline
\end{tabular}

Source: Field work, 2014
Table 3 shows that $29.1 \%$ of the respondents are of the view that the changes of the landscape is moderately strong, while $32.3 \%$ said it is mild and these changes could lead to erosion over time.

\subsubsection{Forms of Changes Found on the Landscape}

The various forms of changes observed in the study area are shown in Table 4 . The table shows that $42.6 \%$ of the respondents said the erosion is small channel or rills. $31.4 \%$ said sheet erosion, $14 \%$ said all the above and $12 \%$ is deep channels or gully. This implies that the dominant type of erosion in the study area and its environs is rill erosion.

Table 4. Forms of Changes Found on the Landscape.

\begin{tabular}{lll}
\hline Options & Frequency & Percentage of the Total \\
\hline Sheet & 47 & 31.4 \\
Small Channels (rills) & 64 & 42.6 \\
Deep Channels (Gully) & 18 & 12.0 \\
All of the above & 21 & 14.0 \\
Total & 150 & 100.00 \\
\hline
\end{tabular}

Source: Field work, 2014

\subsubsection{Features on Which the Changes Were Observed}

This shows the features on which the changes were observed. Table 5 shows that $36.6 \%$ of the respondents are of the view that the effects are on agricultural productivity, $27.4 \%$ agreed on roads, $19.4 \%$ on building and $16.6 \%$ on all of the above.

Table 5. Features on which the Changes was Observed.

\begin{tabular}{lll}
\hline Options & Frequency & Percentage of the Total \\
\hline Agricultural Productivity & 55 & 36.6 \\
Buildings & 29 & 19.4 \\
Roads & 41 & 27.4 \\
All of the above & 25 & 16.6 \\
Total & 150 & 100.00 \\
\hline
\end{tabular}

Source: Field work, 2014

The above findings are clear manifestation that the objectives set and the relationship between soil erosion and human activities have held true. That erosion has significant relationship on human activities: This is because there is loss of soil more rapidly than it is formed through natural processes. This result in losses of soil organic matter, fertility and water holding capacity.

\section{Conclusion}

Erosion is dominant on agricultural productivity, which means that agricultural productivity will be on the decline. The effect of soil erosion is on the increase despite remedial measures taken by farmers to control it. Socially, problems associated with the persistent erosion in the affected areas result in declining standard of living as there is low yield per hectare.

\section{Acknowledgements}

The authors would like to thank the staff of the 
Department of Pollution Control and Environmental Health, Federal Ministry of Environment; staff of Erosion, Flood and Coastal Zone Management and the staff at the Department of Environmental Management and Geography, Nasarawa State University, Keffi for their immense support and insight during this study.

\section{References}

[1] Ofomata, G. E. K. (1982). "Use and Misuse of Nigeria's Agricultural Land Resources". Chapter 3/2, pp. 119-130 of -F. O. C. Ezedinma et at (eds.): Efficient Use of Nigerian Land Resources. Federal Department of Agric. Land Resources, Kaduna.

[2] Adedeji A. (2000). The politics on Erosion issue (ed.) in contemporary issues in Environmental Studies. Jimoh. H. I. and Ifabiyi I. P. Haytee Press, Ilorin.

[3] FAO/ISRIC/ISSS (1998). World Reference Base for Soil Resources. World Soil Resources Report, No. 84. Rome, FAO.

[4] Gruver, J. B. (2013) Prediction, Prevention and Remediation of Soil Degradation by Water Erosion. Nature Education Knowledge 4 (12): 2.

[5] Kumar, Hemant \& Pani, Padmini. (2012). Effects of soil erosion on agricultural productivity in semi-arid regions: The case of Lower Chambal Valley. Journal of Rural Development. 32. 165-184.

[6] FAO. (2019). Soil erosion: the greatest challenge to sustainable soil management. Rome. 100 pp. Licence: CC BYNC-SA 3.0 IGO.

[7] Panagos P, Standardi G, Borrelli P, Lugato E, Montanarella L, \& Bosello F. (2018). Cost of agricultural productivity loss due to soil erosion in the European Union: From direct cost evaluation approaches to the use of macroeconomic models. Land Degrad Dev. 2018; 1-14. https://doi.org/10.1002/ldr.2879

[8] Scoones, I., and C. Toulmin. 1999. "Policies for Soil Fertility Management in Africa." Report prepared for the Department for International Development, London, by the Institute for
Development Studies (IDS) and the International Institute for Environment and Development (IIED).

[9] Mazzucato, V. and D. Niemeijer (2000a) "The cultural economy of soil and water conservation: Market principles and social networks in eastern Burkina Faso." Development and Change 31 (4): 831-855.

[10] Fairhead, J. and M. Leach (1996) Misreading the African landscape: Society and ecology in a forest-savanna mosaic. Cambridge University Press, Cambridge.

[11] Vigiak O., Sterk G., Romanowicz R. J., Beven K. J. A semiempirical model to assess uncertainty of spatial patterns of erosion. Catena. 2006; 66 (3): 198-210.

[12] Strahler AN (1952) Hypsometric analysis of erosional topography. Geol Soc Amer Bull 63: 1117-1142.

[13] White, P. J. 1986. A review of soil erosion and agricultural productivity with particular reference to grain crop production in Queensland. J. Aust. Inst. Agric. Sci. 52: 12-22.

[14] Wikipedia (2019). Erosion. Available online at https://en.wikipedia.org/wiki/Erosion (Accessed: September $21,2019)$.

[15] Akanro. J. (1985). Data gathering for Sheet Erosion Mapping and Control, Federal Department of Agriculture, Land Resources workshop.

[16] Faniran, A. and Areola, O. O. (1976), Essentials of Soil Study, Heinemann, Ibadan, Nigeria.

[17] Igbozuruike, U. M (1990). Socio-economic impact of Soil Erosion, Paper Presented to National Seminar on Erosion ravage in south East in Nigeria, quest for solution. Owerri, Nigeria.

[18] Constantinesco I. (1976) Soil conservation practices, FAO, Soil Bulletin 30, Rom.

[19] Chinedu, P. U. (2018). Secured Cloud-Based Framework for ICT Intensive Virtual Organisation. Approved by: Owerri, Nigeria, Federal University of Technology Owerri, Diss., 2008. Beau Bassin, Mauritius: LAP LAMBERT Academic Publishing. ISBN: 978-613-9-82456-4, Published: April 22, 2018. 